Arqueología y Sociedad,

№ 20, 2009

\title{
CARACTERIZANDO LA CERÁMICA TARDÍA DE LA CUENCA BAJA DEL RÍO NEGROMAYO (LUCANAS- AYACUCHO): APORTES PRELIMINARES A PARTIR DE LA CERÁMICA DEL SITIO ARQUEOLÓGICO DE CANICHI
}

\author{
Sonia Berrocal Flores*
}

\begin{abstract}
Resumen
Este trabajo es el resultado del estudio de una colección cerámica de superficie del sitio arqueológico de Canichi, el cual se encuentra ubicado en la cuenca baja del río Negromayo, distrito de Andamarca, al sur de la Región Ayacucho.

Presentamos el registro de formas cerámicas y los grupos de pastas. A nivel estilístico se realiza una comparación con los estilos que para los períodos Intermedio Tardío y Horizonte Tardío definen, Katharina Schreiber para el valle del Sondondo y otros autores para zonas aledañas. La comparación estilística incluye, además, la revisión de una colección cerámica recolectada por William Isbell al Norte de nuestra área de estudio, en la década del 70.

El análisis de estas colecciones ha servido para la caracterización estilística y morfológica del material cerámico del sitio de Canichi; que muestra la presencia de algunos estilos registrados en la zona de Arequipa, específicamente en los valles del Colca y Cotahuasi.
\end{abstract}

\section{Palabras Clave}

Cuenca del Negromayo, alfar, cerámica, período Intermedio Tardío, período Horizonte Tardío.

\begin{abstract}
This study is an analysis of surface ceramic collection from the archeological site of Canichi, which is located in the lower basin of the Negromayo River, in the district of Andamarca, south of the region of Ayacucho.

We present a registry of ceramic forms and paste groups. Based on a stylistic level, a comparison is performed between the Intermediate and Late Horizon periods, which are defined by Katherine Schreiber and other authors for the valley of Sondondo and other surrounding areas. In addition, the stylistic comparison includes the revision of the ceramic collection originally collected by William Isbell in the 1970 s, in an area to the north of our study.

The results of this collection help identify stylistic and morphological characteristics of ceramic materials from the Canichi site. The results show the presence of various registered styles in the zone of Arequipa, specifically the Colca and Cotahuasi Valleys.
\end{abstract}

Keywords

The Negromayo basin, potter, ceramic, Late Intermediate Period, Late Horizon Period.

* Estudiante de la Escuela Académico Profesional de Arqueología. UNMSM.

Correo electrónico: guiselbf_17@yahoo.es 


\section{INTRODUCCIÓN}

Este artículo forma parte de una investigación realizada en la sur del departamento de Ayacucho, en el sitio arqueológico de Canichi, ubicado en la margen izquierda del río Negromayo, distrito de Carmen Salcedo - Andamarca, provincia de Lucanas (Fig. 1). La iniciativa de este estudio parte del interés de caracterizar el material cerámico encontrado en superficie, en un sitio poco investigado a nivel arqueológico, para los períodos Intermedio Tardío y Horizonte Tardío.

El sitio de Canichi se encuentra emplazado en un promontorio de $240 \mathrm{Km}^{2}$ de extensión, rodeado de andenes y ubicado muy cerca al río Negromayo. Según los restos arquitectónicos y estructuras asociadas, tendría una ocupación prolongada, posiblemente desde el Horizonte Medio, a juzgar por la presencia de dos muros altos que se asemejan a los del sitio de Wari. Las evidencias del Intermedio Tardío estarían representadas por varios conjuntos de estructuras circulares alrededor de un patio, y corredores que conectan estos conjuntos arquitectónicos (vide Cámara, este número). Las evidencias del Horizonte Tardío están constituidas por andenes típicos Inka y también por la presencia de un edificio dividido en dos por un muro céntrico, distinto a la arquitectura local y que podría corresponder a una forma Inka (Schreiber 1993:103).

Las colecciones cerámicas de superficie nos brindan información limitada sobre la ocupación de un sitio arqueológico, por lo cual, en este trabajo, el análisis del

Figura 1. Sitio arqueológico de Canichi, el río Negromayo y la andenería que rodea a la zona. material del sitio de Canichi se realizará en base a la comparación con los estilos establecidos para las zonas cercanas al valle del Negromayo, principalmente en base a los incluidos en las fases definidas por Schreiber para el valle del Sondondo.

El analizar material cerámico de superficie para los últimos periodos prehispánicos resulta complicado debido al contexto social y político en el cual se encuentran inmersos. Antes de la llegada de los Incas, los grupos locales contaron con sus propias manifestaciones materiales. En términos de la producción cerámica se tiene la presencia de los estilos locales y de aquellas vasijas de carácter doméstico que muy probablemente se continuaron produciendo hasta el Horizonte Tardío.

A nivel estilístico y formal, la cerámica Inka es fácil de identificar, y por ello, es usual considerarla como indicador de ocupación Inka en los sitios donde se encuentre cerámica de este tipo en superficie. Es también usual que, cuando además de la cerámica de estilo local se encuentra cerámica de manufactura llana y sin decoración, se asigne el sitio sólo al periodo Intermedio Tardío. Para un sitio nada investigado a nivel arqueológico resulta imprescindible, en

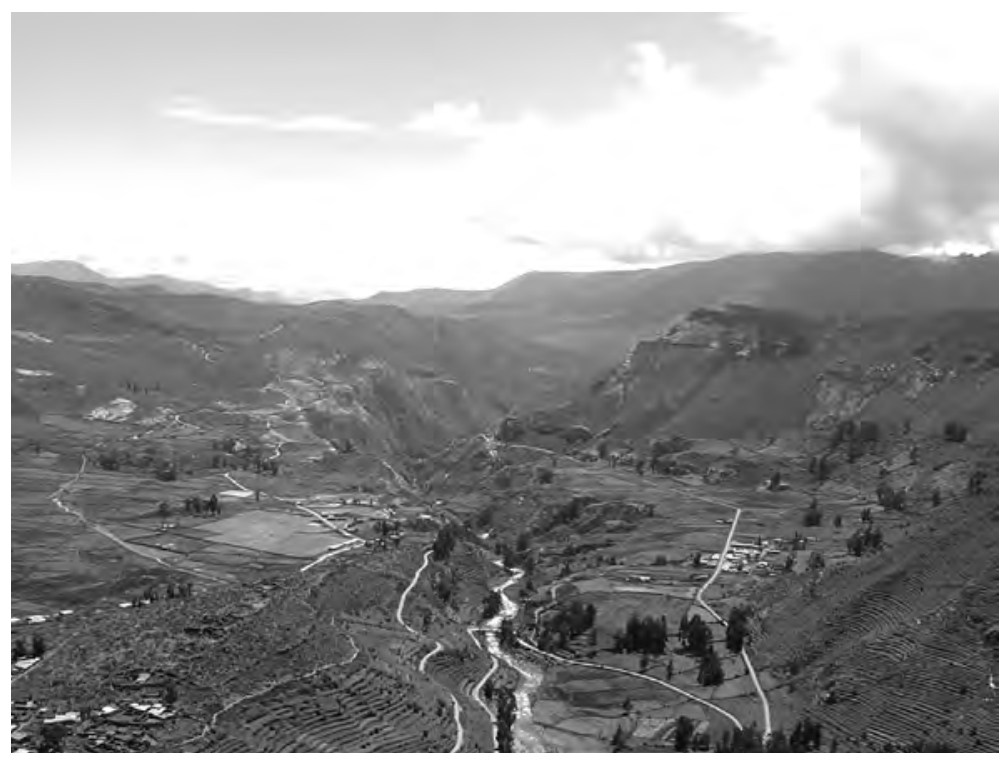


primer lugar, caracterizar la cerámica local con sus respectivos estilos y la cerámica llana sin decoración; luego identificar si éstos continúan durante la ocupación Inka.

\section{MATERIAl COMPARATIVO}

Los periodos dentro de los cuales se esta realizando la comparación corresponde a los períodos Intermedio Tardío y Horizonte Tardío. Se realizó la comparación con los estilos definidos para las zonas cercanas al valle del Negromayo, de acuerdo con la información que ha sido publicada hasta el momento. De esta manera, en el norte de Ayacucho tenemos el material denominado Chanka, con sus respectivos estilos para el Intermedio Tardío y Horizonte Tardío (Lumbreras 1974; González Carré 1992). Para la zona norte de Arequipa se tienen los trabajos de Justin Jennings y Willie Yépez (2009), Paweł Buda (2007), y Steve Wernke (2003) que muestran los estilos presentes en la zona.

También presentamos el material que recolectó Isbell de los sitios de Millpo, Aya Moqo y Willka Qawana, del valle de Sondondo, próximo al de Negromayo (Fig. 2), que se encuentran dentro de las colecciones custodiadas por el Museo de Arqueología y Antropología de la Universidad Nacional Mayor de San Marcos,

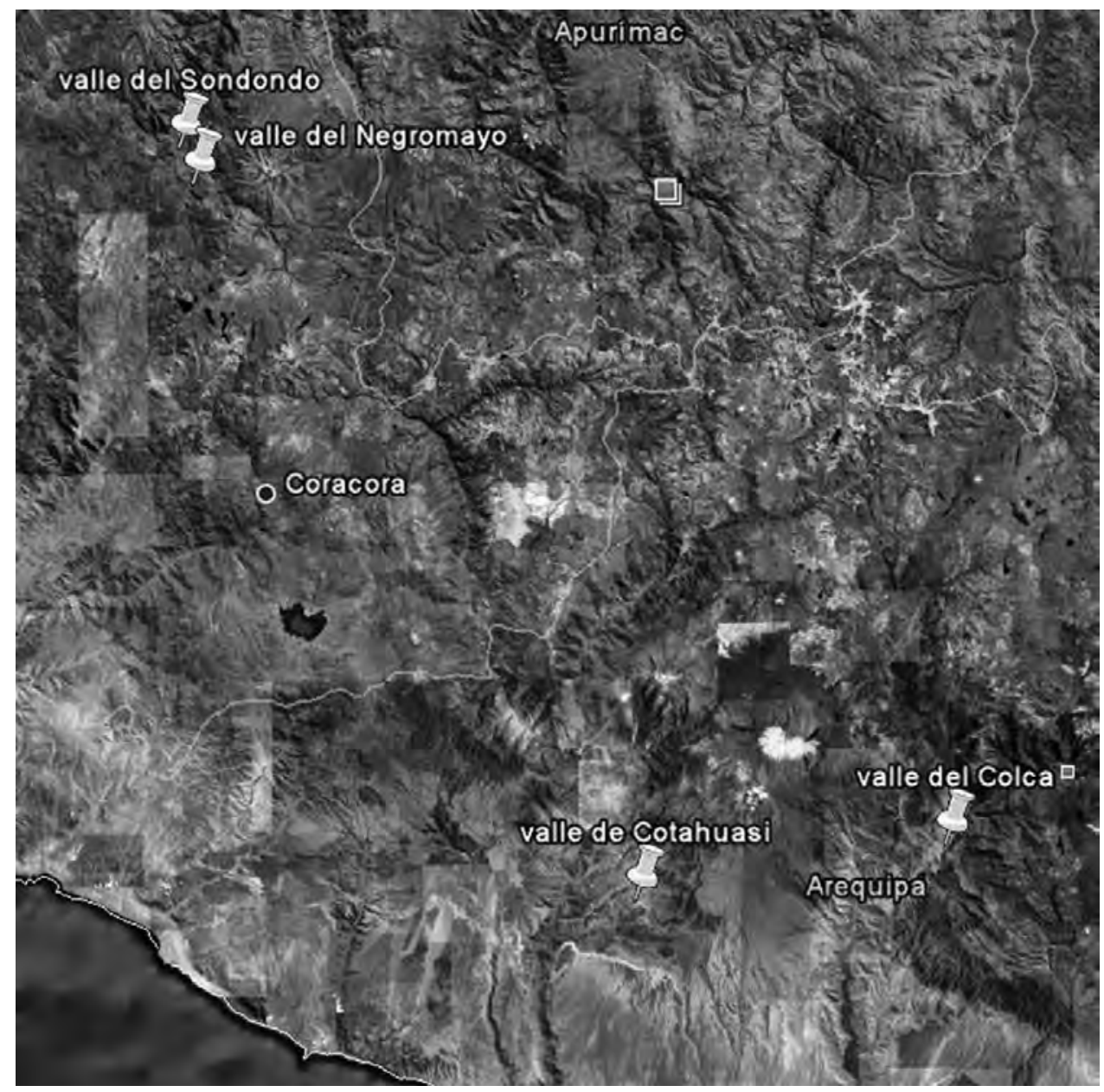

Figura 2. Mapa de ubicación del sitio de Canichi y de los sitios cuyos materiales fueron usados para la comparación. 
para realizar la comparación con los estilos mencionados en el párrafo anterior.

La comparación principal se desarrollará de acuerdo al esquema cronológico elaborado por Schreiber para el valle de Sondondo, que ella denomina en un primer momento Carahuarazo, donde define 7 fases desde el periodo Inicial hasta el Horizonte Tardío. Este esquema cronológico esta basado en material de excavación del sitio de Jincamocco, un sitio del Horizonte Medio (Schreiber 1992), y de recolecciones de superficie de varios sitios arqueológicos ubicados dentro del valle para definir las fases tardías. Schreiber (1993) establece las fases Toqsa (800. 1200 D. C.) y Jasapata (1200-1532 D. C.) para los períodos Intermedio Tardío y Horizonte Tardío (Cuadro 1). Aunque hemos encontrado material probablemente de la fase Marke, no lo mencionaremos en este trabajo, pues corresponden a las fases 3 y 4 del Horizonte Medio (vide Schreiber 1991), que no es motivo de este trabajo.

\section{FORMA Y FUNCIÓN DEL MATERIAL CERÁMICO}

El material cerámico es tomado como un elemento de filiación cronológico determinante que se utiliza para ubicar a los sitios arqueológicos dentro de los períodos y sociedades conocidos. De aquí parte la importancia de un análisis cuidadoso del material cerámico, teniendo en cuenta que no se pueden relacionar determina- das formas sólo con determinados períodos, sobre todo si hablamos de cerámica utilitaria, pues ésta se encuentra en todos los sitios con ciertas variaciones a través del tiempo (Schreiber 1982: 12), siendo necesario identificar sus cambios estratigráficamente.

Este trabajo consta de un primer análisis de formas y grupos de pastas presentes en los sitios de Canichi, Millpo, Willka Qawana y Aya Moqo que anteriormente no fueron analizados, constituyendo así, un avance para las investigaciones que van a llevarse a cabo en la zona. Aquí mostraremos las formas presentes en estos sitios y la descripción de sus características generales.

Para el material del sitio de Canichi se tiene las siguientes formas:

Platos: Los bordes de platos presentes en $\mathrm{Ca}$ nichi tienen dos variedades respecto a la forma del labio, se puede encontrar los platos de labio plano y redondeado (Fig. 3). La mayoría de ellos presentan un engobe rojo, algunos sólo en el interior y otros, tanto en la superficie interna como externa.

Un fragmento de plato presenta una decoración en forma de franja que se extiende de manera horizontal desde el borde interno hasta el borde externo de color rojo (Fig. 4).

Cuencos: Los labios de los cuencos también varían, existen cuencos con labios redondeados, adelgazados y planos (Fig. 5). Dentro de

\begin{tabular}{|c|c|c|c|}
\hline Período & $\begin{array}{l}\text { Valle Colca } \\
\text { Wernke } \\
(2004)\end{array}$ & $\begin{array}{l}\text { Valle Sondondo } \\
\text { Schreiber } \\
(1992) \\
\end{array}$ & $\begin{array}{c}\text { Norte de Ayacucho } \\
\text { González-Carré } \\
(1992)\end{array}$ \\
\hline $\begin{array}{l}\text { Horizonte } \\
\text { Tardío }\end{array}$ & $\begin{array}{l}\text { Collagua Inka } \\
\text { Collagua III }\end{array}$ & Jasapata & $\begin{array}{l}\text { Inka-Chanka } \\
\text { Aya Orqo }\end{array}$ \\
\hline $\begin{array}{l}\text { Intermedio } \\
\text { Tardío }\end{array}$ & $\begin{array}{l}\text { Collagua II } \\
\text { Collagua I }\end{array}$ & Toqsa & $\begin{array}{l}\text { Arqalla } \\
\text { Qachisqo } \\
\text { Tanta Orqo }\end{array}$ \\
\hline
\end{tabular}

Cuadro 1.Cuadro comparativo de los estilos definidos para Ayacucho y Arequipa. Tomado y modificado de Schreiber (1992), Wernke (2003), González Carré (1992). 
los cuencos con labios redondeados se tiene los fragmentos que presentan engobe rojo, marrón y anaranjado, algunos sólo en una de las superficies y otros, en los dos lados. Dentro de esta forma de vasijas es muy común el decorado a manera de marcas en los bordes y el labio, de colores negros, grises, blancos o cremas (Fig. 6), estos decorados están presentes en los cuencos de bordes redondeados y planos.

También, dentro de los cuencos de labios planos, se tiene dos fragmentos que presentan una decoración particular, uno de ellos, presenta una franja de color rojo en el borde exterior y en la superficie interna presenta engobe rojo, y otro fragmentos que presenta también esta decoración de color rojo en la superficie interna y externa, a manera de franjas con dirección horizontal y luego inclinada hacia el cuerpo (Fig. 7).

Ollas: El labio de las ollas es redondeada, varían entre los que tienen cuellos convexo divergente y cuello convexo vertical (Fig. 8). La mayoría de estas ollas tienen engobe rojo en todo el fragmento y algunos sólo en la superficie externa. No presentan ningún tipo de decoración (Fig. 9).
Se encontró sólo un fragmento de olla con decoración, la cual consiste en una gran franja de color roja que se extiende desde el borde en forma de pestaña en el exterior hasta el borde interior (Fig. 10).

Piruros: Fueron encontrados un tiesto de cerámica de forma circular que se asemeja a un piruro a medio terminar y un fragmento de piruro en el sitio de Canichi, el piruro a medio terminar se encontraba muy erosionado y no permitió observar el tratamiento de la superficie (Fig. 11a). El fragmento incompleto presenta un alisado medio de la superficie con un engobe rojo (Fig. 11b).

Formas presentes en los sitios de Willka Qawana, Millpo y Aya Moqo.

Aya Moqo: Las formas presentes en este sitio constan de cántaros, ollas, y cuencos. El tratamiento de la superficie es alisada, de pasta anaranjada sin engobe, Sólo uno de los fragmentos es de pasta marrón clara con una decoración de líneas marrones oscuras. (Fig. 12)

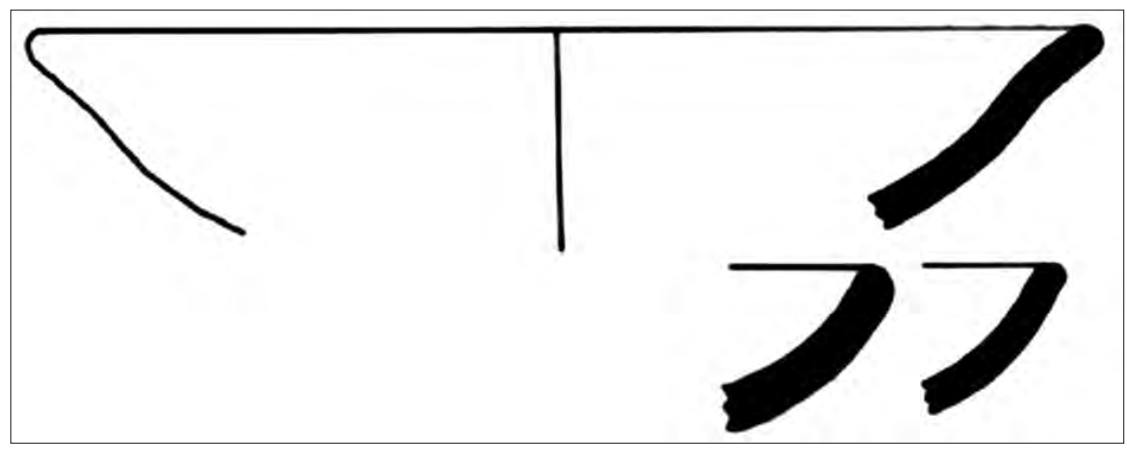

Figura 3. Perfiles de los platos presentes en el sitio de Canichi.

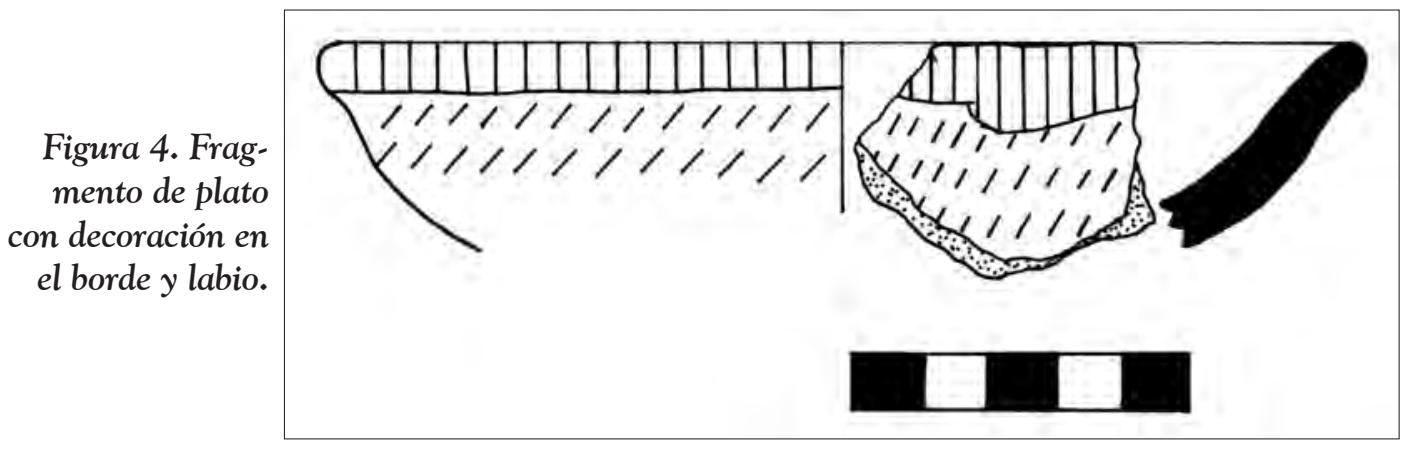




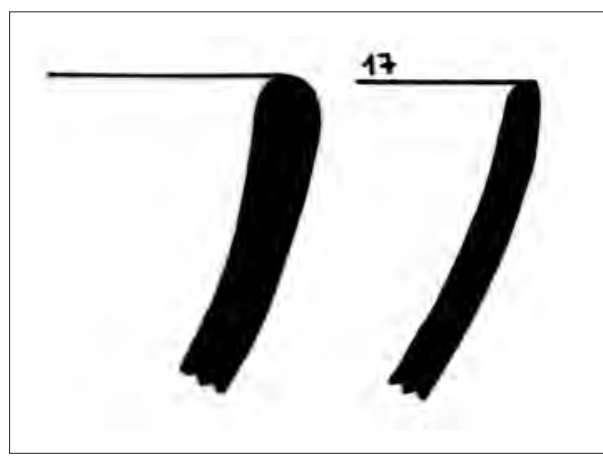

Figura 5. Perfiles de los cuencos presentes en el sitio de Canichi.

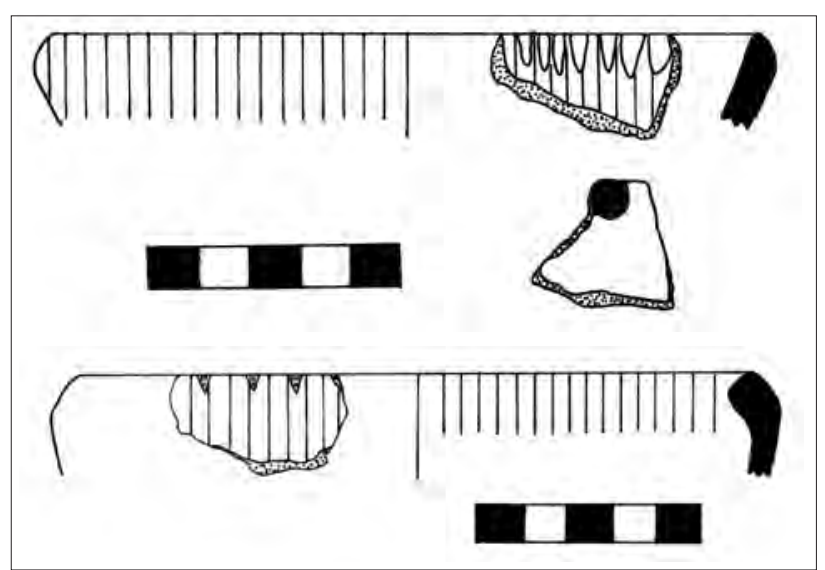

Figura 6. Fragmentos de cuencos con diseños en el borde y labio.

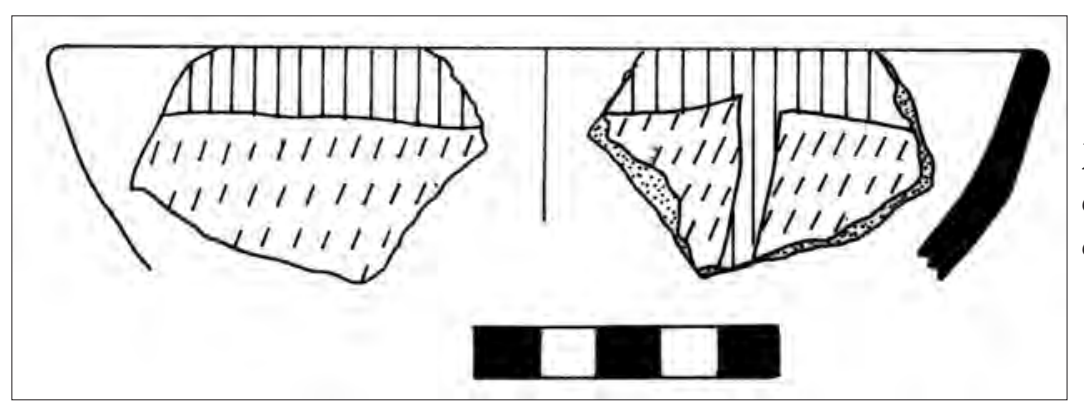

Figura 7. Fragmento de cuenco con decoración en las dos superficies.

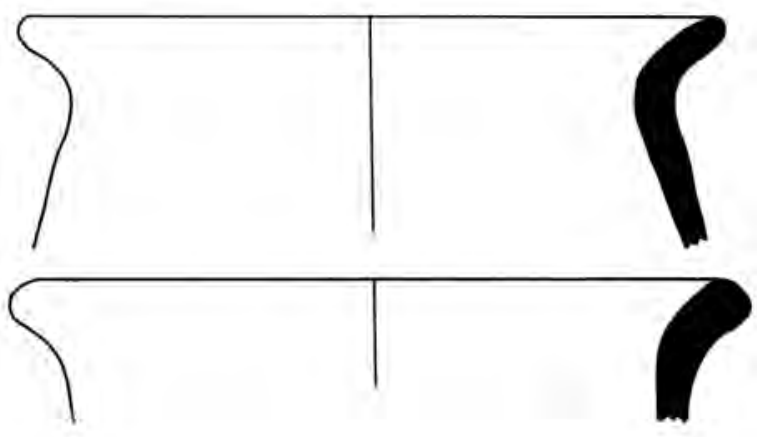

Figura 8. Perfiles de las ollas presentes en el sitio de Canichi.

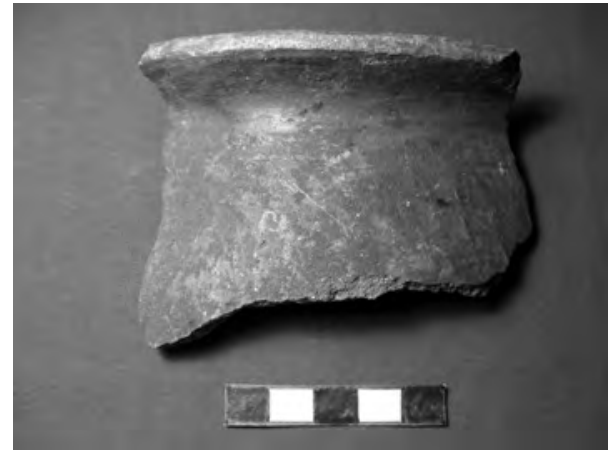

Figura 9. Fragmento de olla sin decoración.
Willka Qawana: En este sitio se tiene en su mayoría bordes de platos, dos de ellos con decoración interna de líneas de color blanco y negro a manera de pequeños círculos en el labio. Estos fragmentos tienen engobe tanto en la superficie interna como externa. (Fig. 13)
Millpo: En este sitio también se tienen bordes de platos, todos ellos que sólo permitieron dibujar su perfil pues eran muy pequeños para determinar su diámetro. Así también, tienen engobe rojo en las dos superficies del utensilio. (Fig.14) 


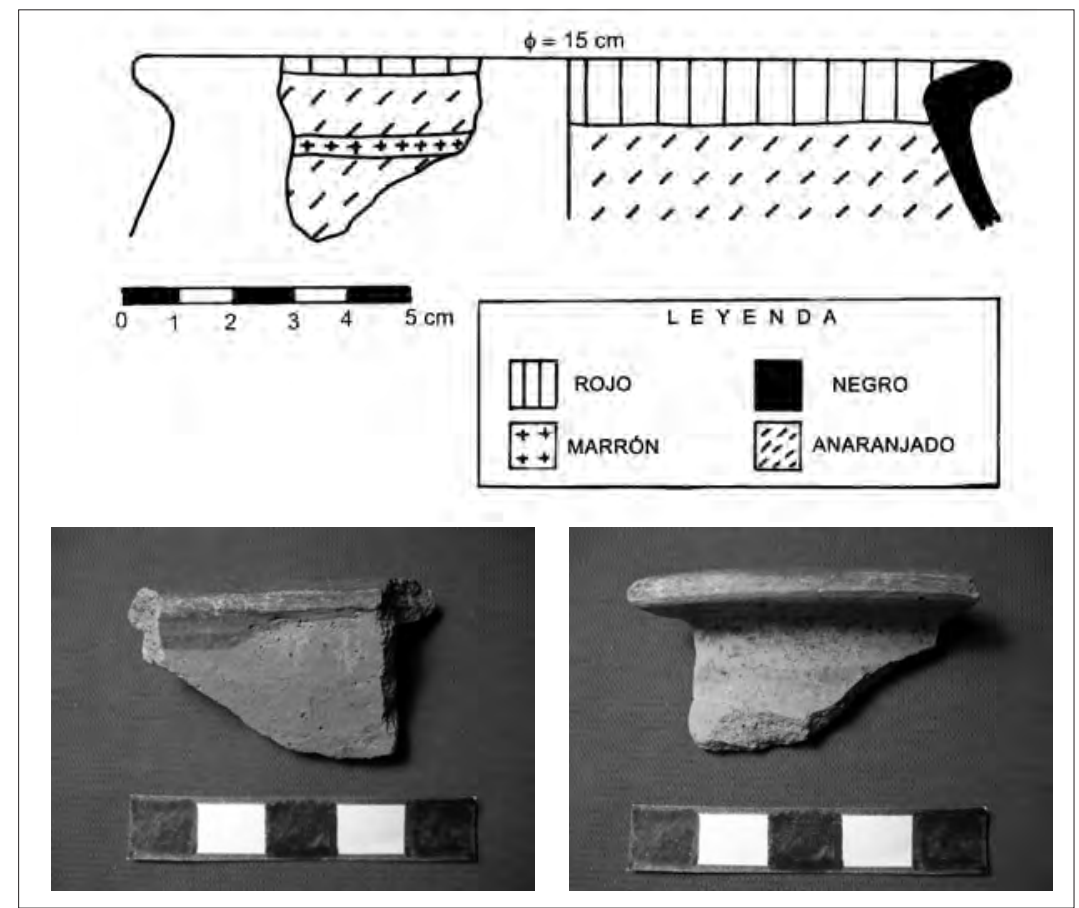

Figura 10. Superficie interna y externa de un fragmento de olla con decoración.

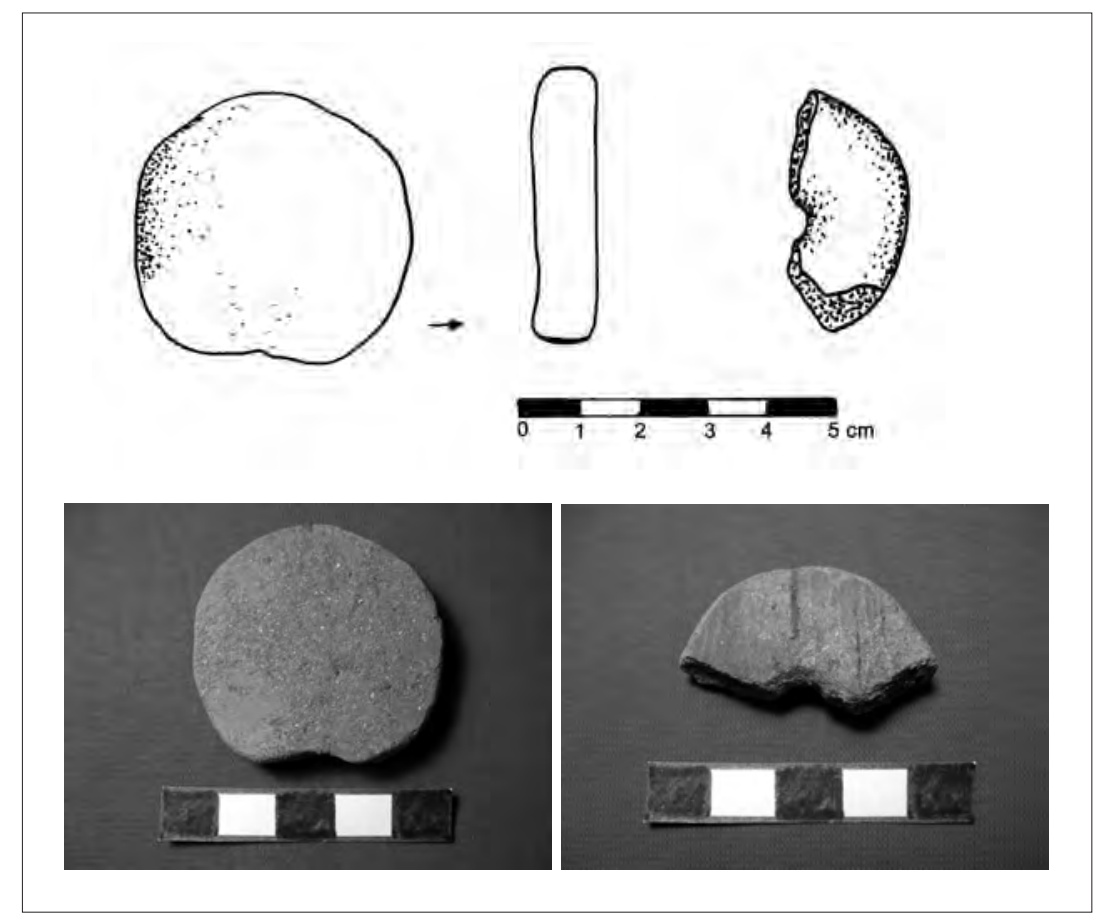

Figura 11. Piruros encontrados en el sitio de Canichi. 


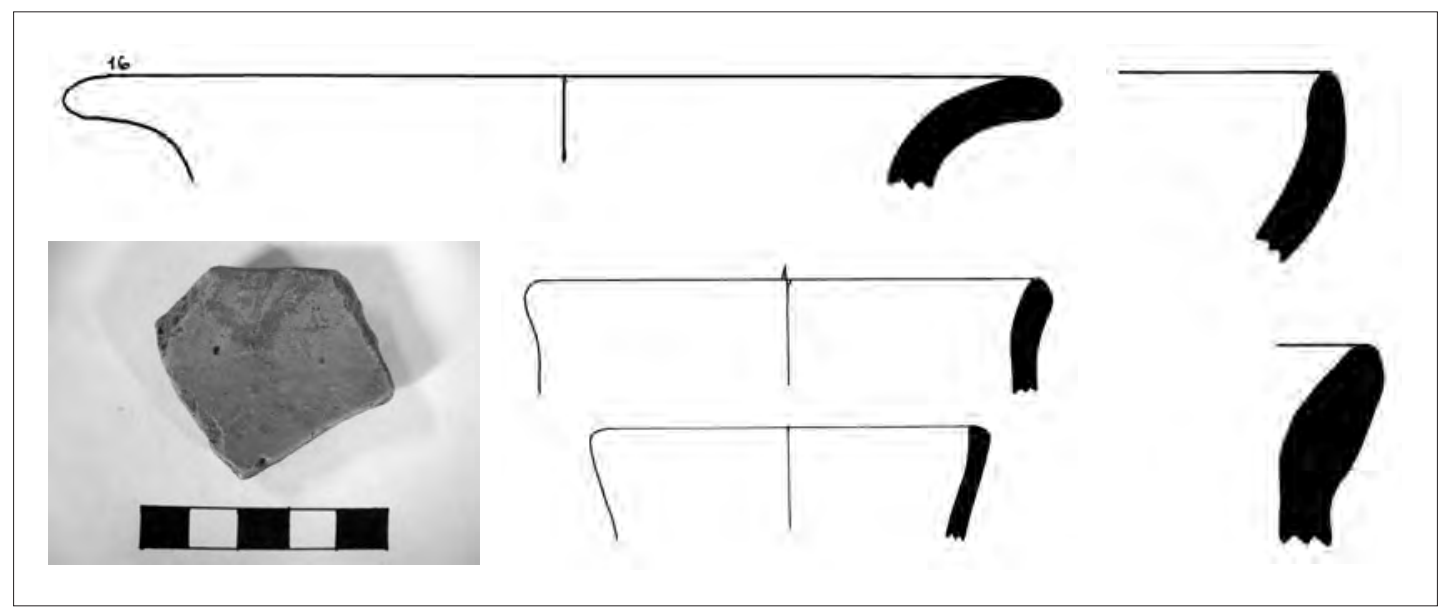

Figura 12. Formas y estilos presentes en el sitio de Aya Moqo

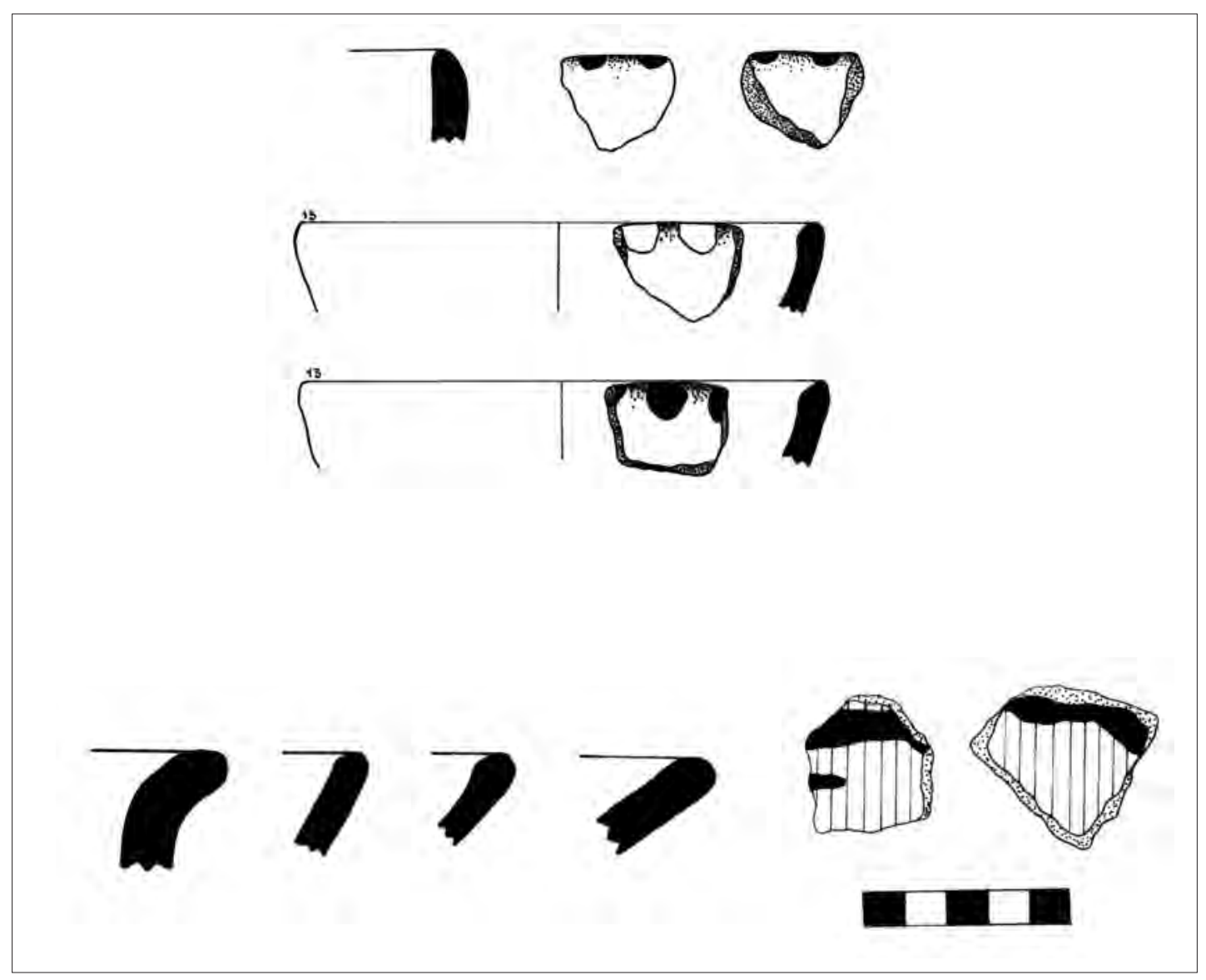

Figura 13. Formas y estilos presentes en el sitio de Willka Qawana 


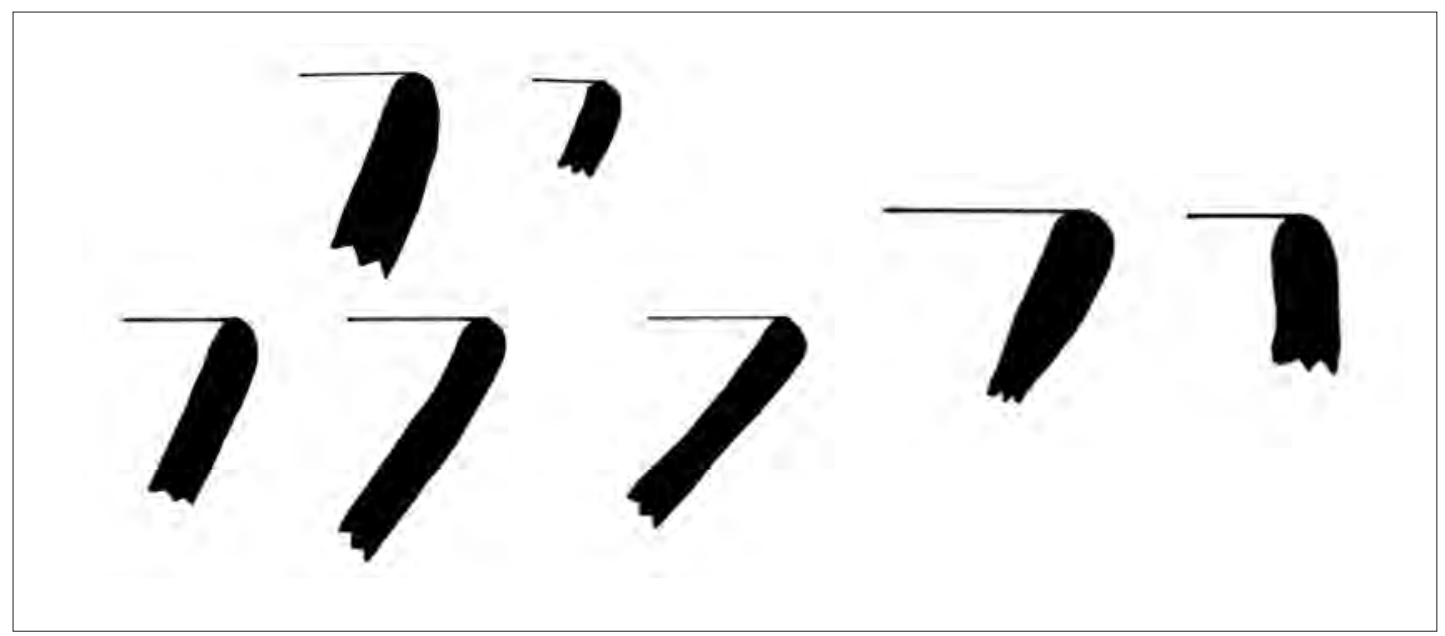

Figura 14. Formas y estilos presentes en el sitio de Millpo

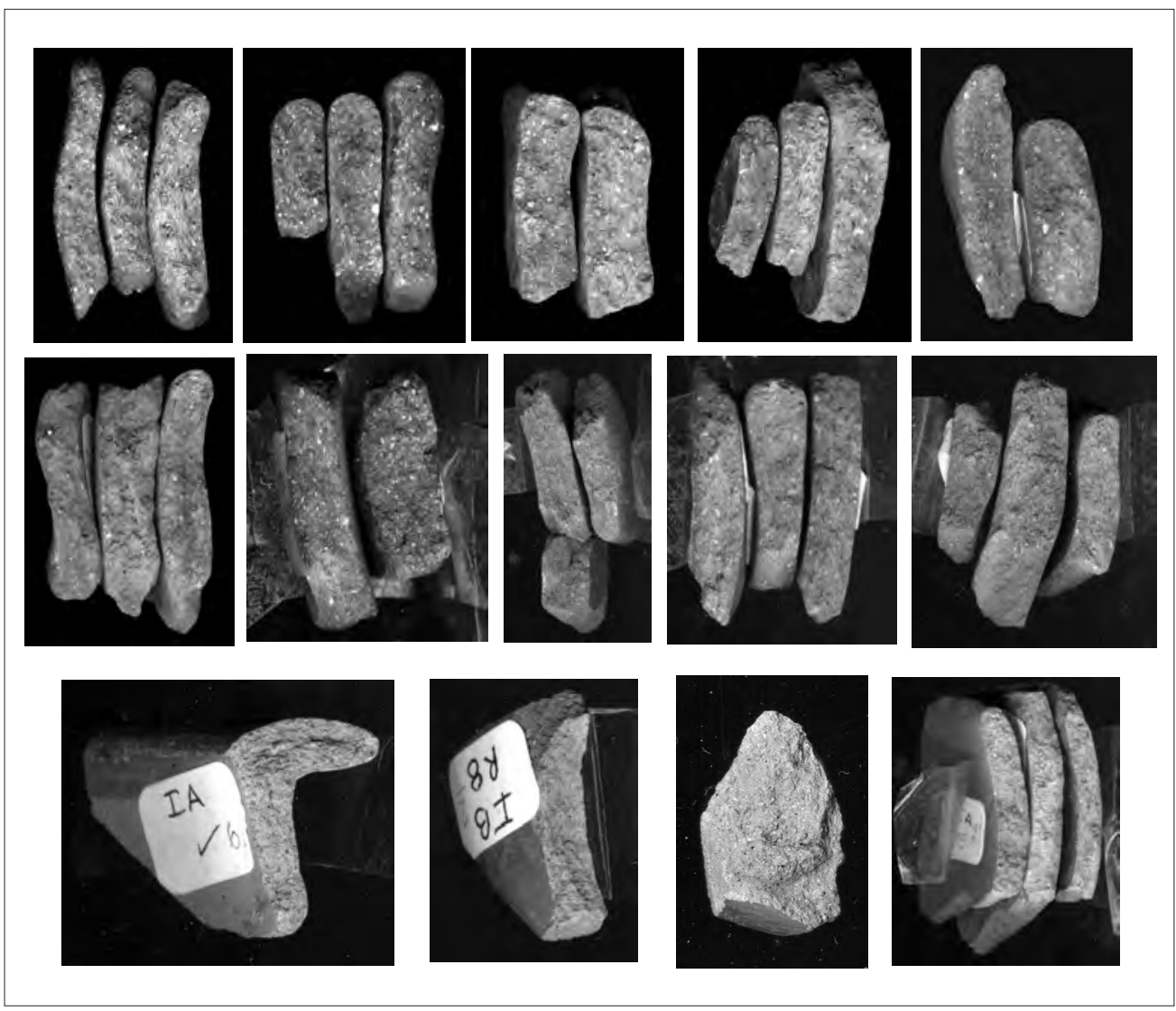

Figura 15. Algunos grupos de pastas identificados en el sitio de Canichi 


\section{Grupos de PAStas del Sitio DE CANICHI}

El análisis de pastas nos ha permitido identificar alrededor de 32 grupos, este análisis es preliminar pues se espera hacer un análisis más profun- do de los mismos. Los grupos han sido nombrados por las letras del alfabeto en mayúsculas, y sus combinaciones cuando las sobrepasan; son las siguientes:

\begin{tabular}{|c|c|c|c|c|c|}
\hline Grupo & $\begin{array}{l}\text { Tamaño de } \\
\text { inclusiones }\end{array}$ & $\begin{array}{c}\text { Porcentaje } \\
\text { de inclusiones }\end{array}$ & Ordenamiento & Redondez & Tipo de inclusiones \\
\hline A & $0.1-0.3$ & $5 \%$ & Pobre & $\begin{array}{l}\text { Sub } \\
\text { redondeado }\end{array}$ & $\begin{array}{l}\text { Cuerpos blancos pequeños, } \\
\text { cristales pequeños, cuerpos negros } \\
\text { ocasionales. }\end{array}$ \\
\hline B & 0.1 & $10 \%$ & Regular & Sub angular & $\begin{array}{l}\text { Cuerpos blancos pequeños, } \\
\text { cristales, piedras negras pequeñas, } \\
\text { cuerpos rojos ocasionales. }\end{array}$ \\
\hline C & $0.1-0.4$ & $10 \%$ & Pobre & $\begin{array}{l}\text { Sub } \\
\text { redondeado }\end{array}$ & $\begin{array}{l}\text { Puntos blancos, cristales, grandes } \\
\text { cuerpos rojos. }\end{array}$ \\
\hline $\mathrm{D}$ & 0.1 & $5 \%$ & Pobre & $\begin{array}{l}\text { Sub } \\
\text { redondeado }\end{array}$ & $\begin{array}{l}\text { Puntos blancos ocasionales, crista- } \\
\text { les, puntos negros. }\end{array}$ \\
\hline E & 0.1 & $10 \%$ & Pobre & Sub angular & $\begin{array}{l}\text { Cuerpos blancos pequeños y } \\
\text { medianos, cristales, puntos negros } \\
\text { y rojos ocasionales. }\end{array}$ \\
\hline $\mathrm{F}$ & $0.1-0.3$ & $5 \%$ & Muy pobre & $\begin{array}{l}\text { Sub } \\
\text { redondeado }\end{array}$ & $\begin{array}{l}\text { Cuerpos blancos medianos, pun- } \\
\text { tos rojos y negros ocasionales. }\end{array}$ \\
\hline G & 0.1 & $10 \%$ & Pobre & Sub angular & Cuerpos blancos, cristales. \\
\hline $\mathrm{H}$ & $<0.1$ & $3 \%$ & Pobre & $\begin{array}{l}\text { Sub } \\
\text { redondeado }\end{array}$ & Puntos blancos, cristales. \\
\hline I & 0.1 & $3 \%$ & Muy pobre & $\begin{array}{l}\text { Sub } \\
\text { redondeado }\end{array}$ & Cuerpos blancos, cristales. \\
\hline $\mathrm{J}$ & 0.1 & $5 \%$ & Muy pobre & - & $\begin{array}{l}\text { Cuerpos blancos, cuerpos negros y } \\
\text { rojos ocasionales. }\end{array}$ \\
\hline K & $0.1-0.2$ & $5 \%$ & Muy pobre & - & $\begin{array}{l}\text { Puntos blancos, cuerpos blancos } \\
\text { medianos, cuerpos grises, cristales } \\
\text { ocasionales. }\end{array}$ \\
\hline $\mathrm{L}$ & $<0.1$ & $3 \%$ & Muy pobre & - & $\begin{array}{l}\text { Puntos blancos, cristales ocasio- } \\
\text { nales. }\end{array}$ \\
\hline M & 0.1 & $10 \%$ & Pobre & Sub angular & $\begin{array}{l}\text { Cuerpos negros, cuerpos rojos, } \\
\text { cuerpos blancos. }\end{array}$ \\
\hline $\mathrm{N}$ & $<0.1$ & $10 \%$ & Pobre & - & $\begin{array}{l}\text { Mica?, puntos negros, puntos } \\
\text { blancos ocasionales. }\end{array}$ \\
\hline $\mathrm{O}$ & 0.1 & $10 \%$ & Muy pobre & - & Puntos negros, cuerpos grises. \\
\hline $\mathrm{P}$ & 0.1 & $5 \%$ & Muy pobre & - & Puntos negros, puntos rojos. \\
\hline Q & $0.1-0.2$ & $5 \%$ & Pobre & Sub angular & $\begin{array}{l}\text { Cuerpos amarillos?, cristales oca- } \\
\text { sionales, cuerpos negros pequeños } \\
\text { ocasionales, mica ocasional. }\end{array}$ \\
\hline
\end{tabular}




\begin{tabular}{|c|c|c|c|c|c|}
\hline $\mathrm{R}$ & $0.1-0.2$ & $20 \%$ & Regular & Sub angular & $\begin{array}{l}\text { Cuerpos blancos, cristales, } \\
\text { cuerpos negros, cuerpos rojos } \\
\text { esporádicos. }\end{array}$ \\
\hline S & 0.1 & $3 \%$ & Muy pobre & $\begin{array}{l}\text { Sub } \\
\text { redondeado }\end{array}$ & $\begin{array}{l}\text { Cuerpos blancos ocasionales, } \\
\text { puntos negros, cuerpos grises. }\end{array}$ \\
\hline $\mathrm{T}$ & 0.1 & $10 \%$ & Pobre & Sub angular & $\begin{array}{l}\text { Cuerpos blancos ocasionales, } \\
\text { cristales. }\end{array}$ \\
\hline $\mathrm{U}$ & $<0.1$ & $5 \%$ & Regular & - & $\begin{array}{l}\text { Cuerpos pequeños, cuerpos } \\
\text { blancos ocasionales y brillantes, } \\
\text { cristales ocasionales. }\end{array}$ \\
\hline $\mathrm{V}$ & $<0.1$ & $3 \%$ & Pobre & - & $\begin{array}{l}\text { Cuerpos negros ocasionales, } \\
\text { cristales ocasionales. }\end{array}$ \\
\hline W & $0.1-0.3$ & $10 \%$ & Muy pobre & $\begin{array}{l}\text { Sub } \\
\text { redondeado }\end{array}$ & $\begin{array}{l}\text { Cuerpos blancos, cuerpos negros } \\
\text { pequeños, cuerpos grises peque- } \\
\text { ños. }\end{array}$ \\
\hline $\mathrm{X}$ & $<0.1$ & $2 \%$ & Regular & - & Cuerpos rojos ocasionales. \\
\hline Y & $0.1-0.2$ & $10 \%$ & Muy pobre & $\begin{array}{l}\text { Sub } \\
\text { redondeado }\end{array}$ & $\begin{array}{l}\text { Cuerpo blancos grandes ocasio- } \\
\text { nales, cuerpos rojos ocasionales, } \\
\text { cristales. }\end{array}$ \\
\hline Z & 0.1 & $10 \%$ & Pobre & $\begin{array}{l}\text { Sub } \\
\text { redondeado }\end{array}$ & $\begin{array}{l}\text { Cuerpos blancos, cuerpos negros } \\
\text { ocasionales, cuerpos rojos ocasio- } \\
\text { nales. }\end{array}$ \\
\hline $\mathrm{AA}$ & $0.1-0.2$ & $5 \%$ & Pobre & Sub angular & $\begin{array}{l}\text { Cuerpos blancos grandes y peque- } \\
\text { ños, cuerpos negros ocasionales. }\end{array}$ \\
\hline $\mathrm{AB}$ & 0.1 & $5 \%$ & Muy pobre & Sub angular & $\begin{array}{l}\text { Cuerpos blancos ocasionales, cris- } \\
\text { tales pequeños, cuerpos granates } \\
\text { ocasionales. }\end{array}$ \\
\hline $\mathrm{AC}$ & $0.1-0.2$ & $5 \%$ & Muy pobre & Sub angular & Cuerpos rojos, cuerpos blancos. \\
\hline $\mathrm{AD}$ & 0.1 & $5 \%$ & Pobre & $\begin{array}{l}\text { Sub } \\
\text { redondeado }\end{array}$ & $\begin{array}{l}\text { Cuerpos granate medianos, crista- } \\
\text { les, cuerpos blancos ocasionales, } \\
\text { cuerpos negros ocasionales. }\end{array}$ \\
\hline $\mathrm{AE}$ & 0.1 & $10 \%$ & Pobre & Sub angular & $\begin{array}{l}\text { Cuerpos blancos ocasionales, } \\
\text { cuerpos negros ocasionales. }\end{array}$ \\
\hline $\mathrm{AF}$ & 0.1 & $5 \%$ & Regular & Sub angular & $\begin{array}{l}\text { Cuerpos blancos, cristales, cuer- } \\
\text { pos negros brillantes. }\end{array}$ \\
\hline
\end{tabular}

\section{Cuadro 2. Características de los grupos de pastas definidas del sitio de Canichi.}

Se observa la presencia de pastas foráneas que coinciden con formas de vasijas Inka, como lo son los grupos $\mathrm{M}, \mathrm{N}$ y O (Cuadro 2). Aunque sólo contamos con un fragmento por cada tipo de pasta creemos que es necesario realizar un análisis físico de los fragmentos para poder corroborar esta proposición.

\section{COMPARACIÓN ESTILÍSTICA DEL MATERIAL}

La zona sur del actual departamento de Ayacucho ha sido poco investigada a nivel arqueológico, por lo cual, el establecer estilos para esta zona resulta difícil por la ausencia de este tipo de trabajos. En base a las descripciones de los estilos para los periodos tardíos que menciona 
Schreiber, identificamos fragmentos que podrían corresponder a las fases Marke, Toqsa y Jasapata (Fig. 15), pero sólo nos centraremos en los que corresponden a las dos últimas fases, quedando aún por afinar los estilos correspondientes a cada una de ellas (Schreiber 1982:17).

Según las descripciones que Schreiber (1982:15) presenta para la fase Toqsa, hemos

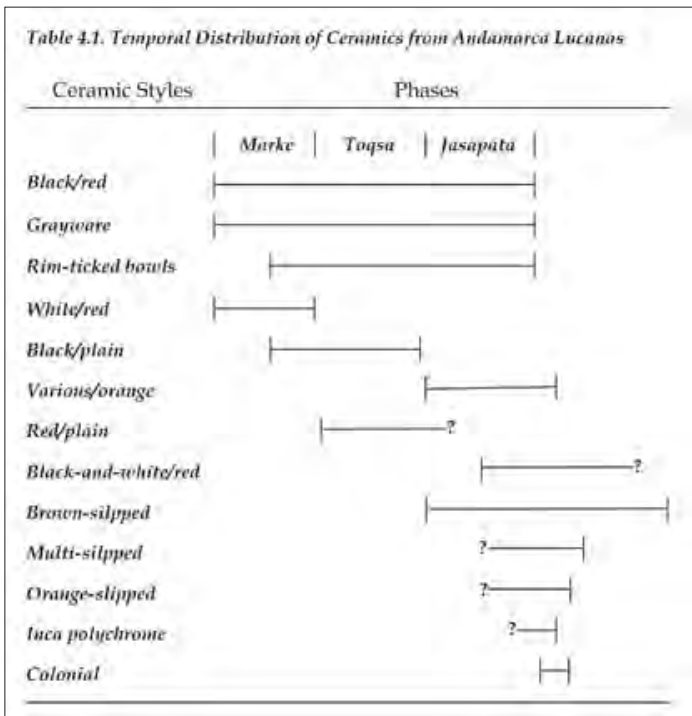

Figura 16. Distribución de los estilos cerámicos dentro de las tres fases generales. Fuente: Schreiber (1993:81)

reconocido aquellos fragmentos que tienen una decoración de color negro sobre rojo, específicamente aquellos diseños que se encuentran en el cuerpo de la vasija, que aparecería desde la fase Marke hasta la fase Jasapata (Schreiber 1993:80). Los fragmentos corresponden a los sitios de Canichi, y Willka Qawana (Fig. 16). Este tipo de decoración no sólo se registra para la zona de Ayacucho como se describe para el estilo Aya Orqo (Lumbreras1974:219), sino también para la zona de Arequipa dentro de los estilos Collagua I y Collagua II (Wernke 2003:485), además del estilo Runarina (Jennings y Yépez 2009:429), el cual consideran que refleja la influencia de Chuquibamba (Jennings y Yépez 2009:434) en el Valle de Cotahuasi, Arequipa.

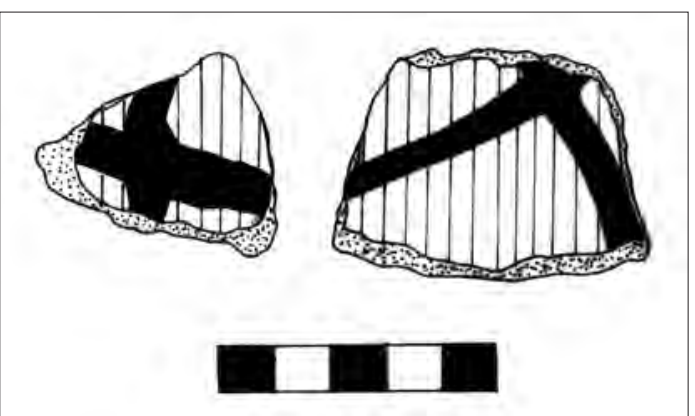

Figura 17. Fragmentos con decoración de diseños de color negro sobre la superficie roja.

Así también, lo que resulta interesante recalcar es que, la denominada cerámica Chanka (González Carré 1992), muy trabajada y registrada en el norte de Ayacucho, no se encuentra bien definida en el material recuperado hasta ahora en nuestra área de estudio. El único trabajo que ha presentado una vasija Chanka del estilo Aya Orqo, y que se asemeja a varias ollas que se encuentran en el museo Rikchariy del distrito de Andamarca (Fig. 17) se encuentra en el trabajo de Valdez publicado en el año 2002, cuya semejanza si corresponde sólo a ese estilo.

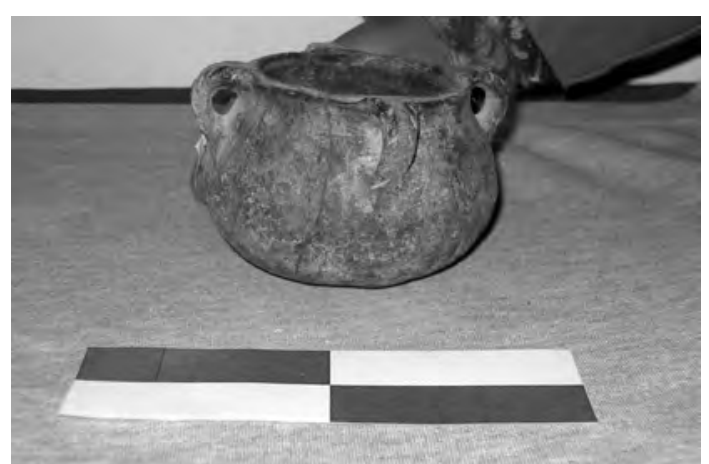

Figura 18. Olla con cuatro asas que se encuentra en el museo Rikchariy de Andamarca.

Así también se encuentra dentro de la colección de este museo, una aplicación en forma de rostro que podría asemejarse a los rostros que se encuentran en los golletes de las vasijas Chanka, aunque si somos más minuciosos, presentan ciertas diferencias como la forma de la boca y la nariz (Fig. 18). Estos rostros se en- 

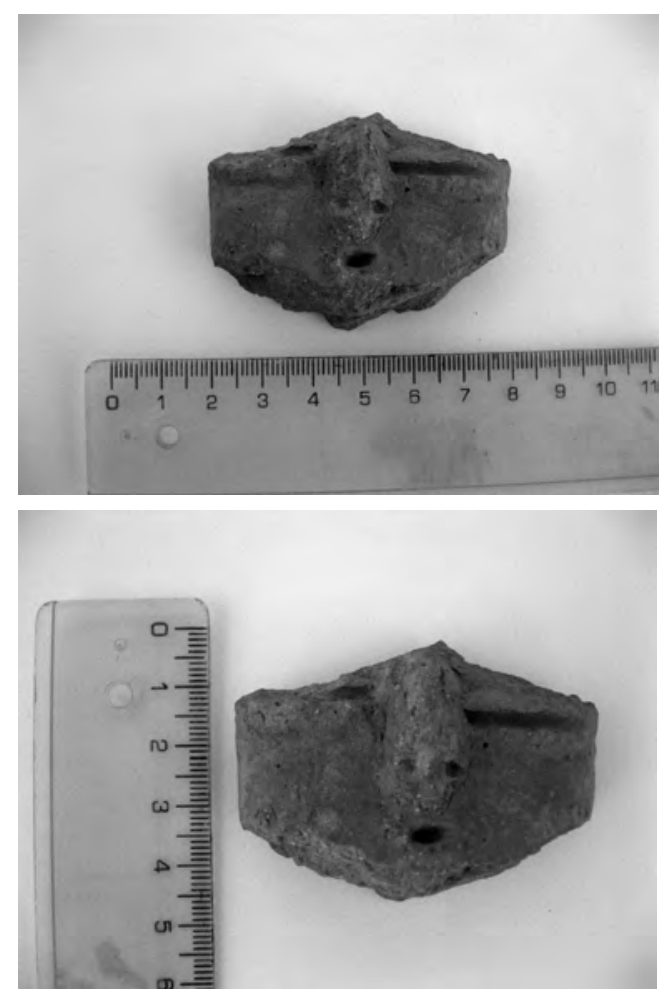

Figura 19. Aplicación de rostro encontrado en el sitio de Canichi.

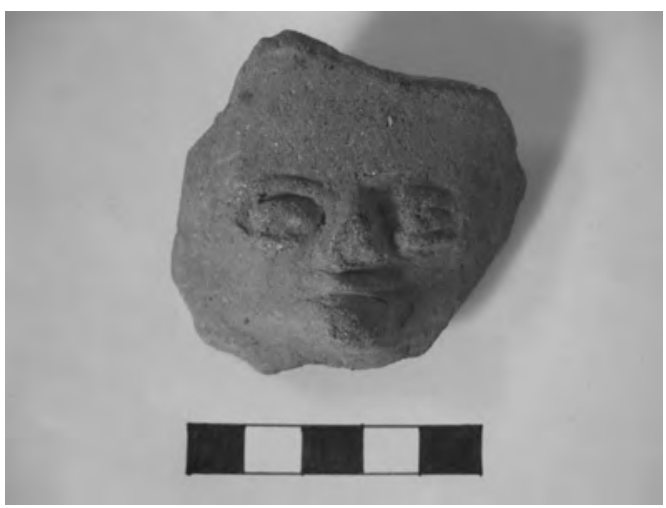

Figura 20. Aplicación de rostro moldeado del sitio de Willka Qawana.

cuentran dentro de los estilos Qachisqo y Arqalla, a manera de aplicaciones plásticas, en cambio, en el rostro que fue encontrado en Canichi sólo la nariz podría considerarse una aplicación plástica, ya que los ojos y la boca son incisos.
En el sitio de Willka Qawana se tiene también la aplicación de un rostro, el cual parece haber sido moldeado, diferenciándose así, del rostro encontrado en Canichi y de las caras gollete Chanka (Fig. 19).

Tenemos también fragmentos de cuencos y platos que presentan una decoración de líneas de color negro, crema y gris en los bordes y labios. Este tipo de decoración no sólo se encontró en el material del sitio de Canichi (Fig. 6) sino también en el material del sitio de Willka Qawana recolectado por Isbell. (Fig. 20). Esta decoración en su variedad de líneas blancas sobre rojo, que nosotros creemos podría referirse al color crema, pertenecería a la fase Jasapata (Schreiber 1982:23, Figura 4.6), detalle que en su publicación de 1993 podría corresponderse con el material de la fase Marke, en su variedad del color gris y con borde engrosado (Schreiber 1993:80). Por lo cual, este diseño de decoración en el color negro podría ser parte de una variación dentro de la fase Jasapata y la de color gris para la fase Marke. La decoración de líneas negras podría corresponder también con una variación del estilo Collagua I que se tiene para el valle del Colca (Wernke 2003:493) debido a que presenta estos diseños de líneas negras en el labio, el cual sería interpretado como derivado de Wari para la zona de Arequipa (Wernke 2003:485), aunque, el estilo Collagua I contiene más motivos en el cuerpo de la vasija (Wernke 2003, pág. 493, figura A.24), que marca la diferencia a nivel decorativo. Lo que si es evidente, es el engobe rojo que cubre la superficie interna de la vasija y algunas veces la superficie exterior en los dos casos. El tratamiento de la superficie es en algunos casos alisado y en otros es pulido.

Siguiendo con la clasificación de Schreiber, la fase Jasapata comprende la mitad del período Intermedio Tardío y se extiende hasta finales del período Horizonte Medio. Schreiber ubica dentro de esta fase al estilo Inka Polícromo, vasijas con engobe naranja sin decoración, cerámica con engobe marrón y con múltiples engobes (Schreiber 1993:82), de los cuales, en nuestra 


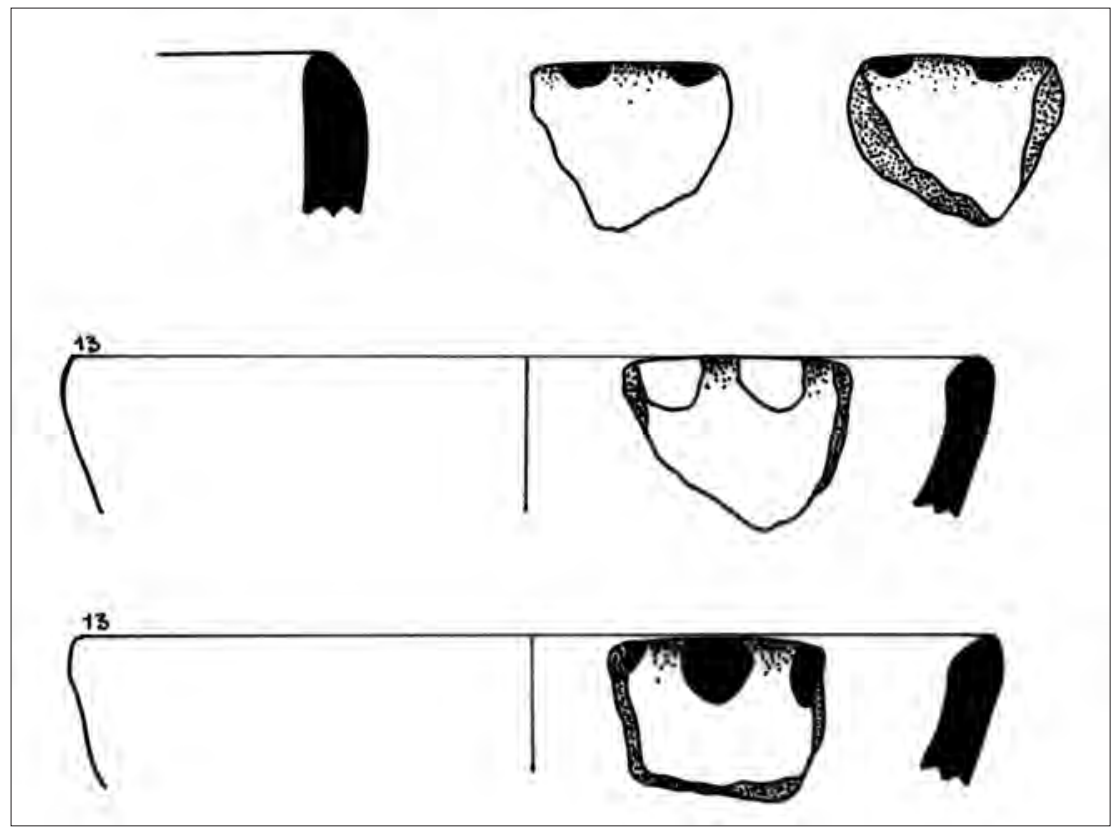

Figura 21. Cuencos decorados del sitio de Willka Qawana

muestra de Canichi, se tiene fragmentos de ollas con engobe marrón y platos con engobe naranja sin ningún tipo de decoración.

Al hablar del período con presencia Inka en la zona, se debe tomar en cuenta que no sólo se encuentra cerámica de tipo imperial en los sitios arqueológicos con esa ocupación, sino también es posible encontrar material foráneo o de manufactura distinta a la local, no sólo a nivel de pastas sino también de tratamiento de las superficies de la vasija y de la utilización de ciertos colores en las decoraciones.

Dentro del material procedente de Canichi, sólo tres fragmentos podrían corresponderse a la época Inka, el primero de ellos ya fue mencionado líneas arriba, se trata de una olla con labio en forma de pestaña y decoración de color rojo (Fig. 10), en segundo lugar, tenemos un fragmento de base de plato, de tratamiento pulido en la superficie interna y externa, con decoración de color rojo (Fig. 21) y por último, tenemos una aplicación en forma de asa de color morado perteneciente, probablemente, a la parte del labio de un plato (Fig. 22). Estos fragmentos han sido fabricados posiblemente en otro lugar, pues, el tipo de arcilla con el cual fueron fabricados es distinto. Su tipo de pasta cerámica se correspondería con los tipos 13, 14 y 15 de nuestra clasificación, las cuales son muy distintas a las pastas que consideramos como locales; además, el tratamiento de superficie fue más fino y cuidadoso.

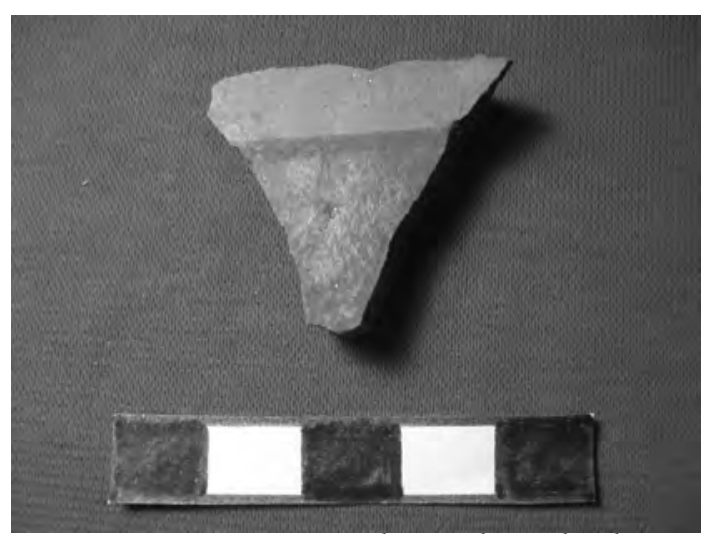

Figura 22. Fragmento de una base de plato, con decoración perteneciente al estilo Inka. 


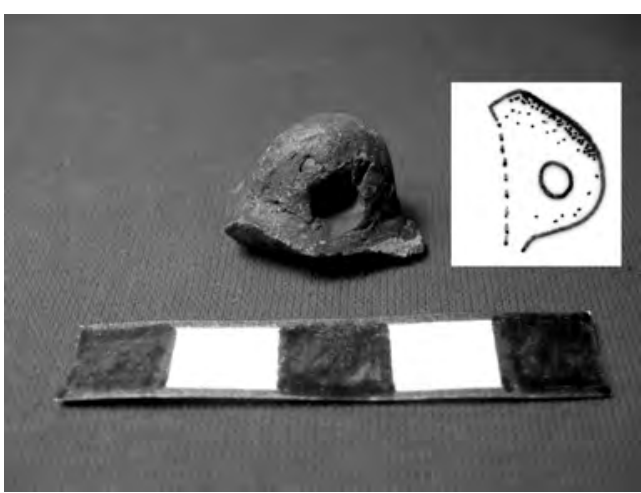

Figura 23. Aplicación de asa de color morado.

También se ha encontrado un fragmento que podría corresponder al estilo Inka dentro del material perteneciente al sitio de Willka Qawana, este fragmento es parte del cuerpo de una vasija y presenta la decoración de unas franjas negras y una franja roja más gruesa sobre una superficie anaranjada (Fig. 23). El tratamiento de la superficie no llega a ser pulida, pero sí podría calificarse como más cuidadosa. Este tipo de decoración se asemeja al material presentado en la publicación de Buda (2007) sobre el sitio de Tompullo - Arequipa, como perteneciente al estilo Inka local (Buda 2007:265).

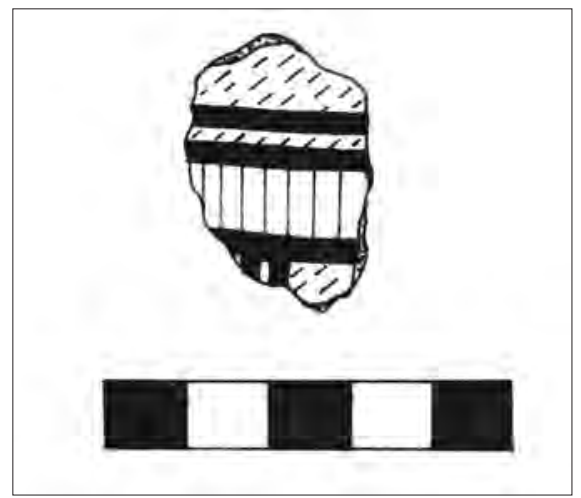

Figura 24. Fragmento del sitio de Willka Qawana con decoración de color negro y rojo sobre superficie anaranjada.

\section{Discusión}

Para explicar el contexto histórico dentro del cual nuestra área de estudio se encuentra inmersa, debemos tomar como primera referencia la información que se presenta para el valle del Sondondo, el cual no está apartado de los acontecimientos que ocurrieron con similares características en otras zonas luego de la caída del Impero Wari. Durante el Intermedio Tardío hubo movimientos de población desde los valles hacia zonas con emplazamientos defendibles, de los cuales, muchos estaban rodeados de grandes muros defensivos, como es el caso del sitio de Toqsa (Schreiber 1987:64). Este período, en el norte de Ayacucho, es identificado en base a la presencia de los sitios que presenta este tipo de características de asentamiento y en base a la cerámica de manufactura sencilla denominada "Chanka" (Lumbreras 1974; González Carré 1992).

Este período resulta problemático, por no haberse excavado sitios correspondientes a esta etapa cerca de nuestra zona de estudio, como lo hubo para la zona de Huancavelica (Lavallée y Julien 1983). Es difícil por lo tanto, que se tenga establecido un orden estratigráfico del material cerámico, además de formas y estilos definidos para los períodos en mención, debido a que las colecciones de superficie nos brindan información que no permite llegar a conclusiones más específicas hasta no excavar el sitio y corroborar las hipótesis, lo cual no quiere decir que no se hayan llevado a cabo este tipo de trabajos y que constituyan un aporte a los estudios de sus respectivas zonas, como por ejemplo el realizado por Hocquenghem y Kaulicke (1995) y Lavallée (1967) para el extremo norte del Perú y la Sierra Central respectivamente.

No nos detendremos mucho para revisar la información respecto a lo que denominan como cerámica Chanka en el norte de Ayacucho, la cual ha sido definida en base a cuatro tipos: Tanta Orqo, Qachisqo, Arqalla y Aya Orqo (González Carré 1992). Pues, ya se ha mencionado en publicaciones anteriores las limitaciones que tiene esta clasificación, pues este ordenamiento estilístico no ha sido demostrado, hasta el día de hoy, estratigráficamente, ni tampoco se ha definido su distribución en el tiempo y en el espacio (Valdez 2000; Valdez 2002). Las descripciones 
que presentan Lumbreras (1974) y González Carré (1992) de los estilos Chanka son objeto de confusión, pues refieren a estilos Chanka en sitios definidos como Inka, y estilos Inka en sitios donde se definieron los estilos Chanka (Valdez 2000: 22) Además, "en el valle de Ayacucho fue común la producción de alfarería simple antes de los Chankas; es precisamente por esta razón que resulta peligroso identificar dicha cerámica como Chanka y estrictamente pre-Inka" (Valdez y Valdez 2002:89) Por lo cual, resulta necesario afinar esta clasificación y su distribución en la Sierra Sur.

Las fases que determina Schreiber (1982; 1991 ; 1993) para el valle del Sondondo requieren un mayor análisis debido a ser de superficie. Los diferentes estilos que conforman estas fases no ayudan a ubicar a los sitios arqueológicos dentro de determinado período y su utilización tiene el mismo sesgo que el material denominado como Chanka. Hemos considerado estas fases sólo como punto de partida hacia un acercamiento a las características del material del sitio de Canichi, teniendo en cuenta su cercanía al valle del Negromayo considerando que debería ser reevaluado con excavaciones en los sitios que dieron nombre a las fases que Schreiber establece.

La presencia Inka, desde el análisis de los objetos materiales, en este caso la cerámica, se muestra mucho más compleja que en el período anterior, pero más investigada a la vez, a nivel tecnológico (D’Altroy et al. 1994; Hayashida 1995; Valdez y Valdez 2002), estilístico y morfológico (Meyers 1975; Bray 2004). En el norte de Ayacucho se identifican estilos que se mantienen en la época Inka desde el Intermedio Tardío (Valdez y Valdez 2002: 89) pues, las tradiciones locales no fueron alteradas ni sustituidas, sino modificadas, adoptando formas o decoraciones propiamente Inka. La identificación de ciertas vasijas Inka en estos sitios y la determinación de su magnitud, determinaría la importancia del lugar para los Inkas y su rol dentro de la organización económica del Imperio Incaico, además de su ubicación política y social para este perio- do (Costin y Earle 1989; Hayashida 1994; Costin y Hagstrum 1995; Bray 2003, 2004).

\section{CONSIDERACIONES FINALES}

Las fases definidas por Schreiber con sus respectivos estilos definidos para el valle del Sondondo merecen una publicación individual que permitan aclarar mejor aquellos estilos ya identificados para poder corroborarlos en excavación, debido a que la información respecto a la cerámica que se tiene para las fases Toqsa y Jasapata en el informe del año 1982 y la publicación del año 1993 no se relacionan completamente, lo que deviene en confusiones al querer identificar los estilos de cada fase. De esta manera se obtendría, una base para las posteriores investigaciones que se realicen en los valles aledaños, y sobretodo, para aquellos sitios que no han sido aún catalogados como pertenecientes al grupo Chanka para el período Intermedio Tardío, dentro de nuestra zona de estudio.

Las formas de vasijas ubicadas en el material analizado, pueden ser calificadas de utensilios domésticos (platos, cántaros, ollas, cuencos), apoyándose en la función a la que están destinadas. Por lo tanto, el sitio de Canichi, así como el sitio de Willka Qawana, Millpo y Aya Moqo, pueden ser considerados como lugares en donde se realizaron labores domésticas. Quedando aún por explicar el significado o papel desempeñado por aquellos objetos cerámicos que salen de esta clasificación, como son las aplicaciones de rostros encontrados en Canichi y Willka Qawana.

Consideramos que, la cerámica que presentamos no se corresponde directamente con las características de la cerámica Chanka, es probable que el grupo o los grupos que se hayan asentado en la zona sur de Ayacucho sea un grupo particular con manifestaciones que revelen su contacto con grupos que se ubicaron al sur de Ayacucho, como por ejemplo, la zona de Arequipa, para el período Intermedio Tardío, quedando aún por determinar las características de estos contactos y su continuidad en el Horizonte Tardío. 
Es posible también que, durante el Horizonte Tardío, debido a los asentamientos mitmaq que se refieren para la zona de Andamarca (Schreiber 1987: 66), revelen la presencia de poblaciones provenientes de los valles de Cotahuasi o del Colca. Lo cual no sólo se evidencia en los estilos, sino también, en la gran diversidad de grupos de pastas presentes en el material analizado.

\section{Agradecimientos}

Debo agradecer en primer lugar, al museo Rikchariy de Andamarca, por habernos proporcionado parte de su material cerámico para fotografiarlo, así como a la Srta. Fátima por su ayuda y aliento en nuestro trabajo arqueológico. Al Museo de Arqueología y Antropología de San Marcos por brindarnos las facilidades para el análisis del material cerámico que recolectó W. Isbell. A Elizabeth Aguirre por su apoyo en el dibujo del material cerámico. Así también a Manuel Aguirre-Morales, Christian Altamirano y Jorge Cámara por sus observaciones a este trabajo.

\section{Bibliografía}

Bray, Tamara

2003 "Inca pottery as culinary equipment: food, feasting, and gender in imperial stage design”. Latin American Antiquity, 14 (1), p. 3-28.

2004 "La alfarería Inka: una comparación entre la cerámica estatal del área del Cuzco y la cerámica de las provincias”. Chungará, Revista de Antropología Chilena, 36 (2), p. 365-374.

Buda, Paweł

2007 "Los sitios de Tompullo 1 y Tompullo 2 a la luz de los trabajos arqueológicos del proyecto 'Condesuyos'. Andes”. Boletín de la Misión Arqueológica Andina 6:239-275.

Costin, Cathy y Timothy Earle

1989 "Status Distinction and Legitimation of Power as reflected in Changing Patterns of Consumption in Late Prehispanic Peru". American Antiquity, 54 (4), p. 691-714.

Costin, Cathy y Melissa Hagstrum

1995 "Standardization, Labor Investment, Skill, and the Organization of Ceramic Production in Late Prehispanic Peru". American Antiquity, 60 (4), p. 619-639.

Enrique González Carré

1992 Los señoríos Chankas. Lima. Universidad Nacional de San Cristóbal de Huamanga. Instituto de Estudios Arqueológicos INDEA.

Hayashida, Frances

1994 "Producción cerámica en el imperio inca: una visión global y nuevos datos". En I. Shimada, ed. Tecnología y organización de la producción de cerámica prehispánica en los Andes. Lima, PUCP, p. 449-476.

Hocquenghem, Ann y Peter Kaulicke

1995 "Estudio de una colección de cerámica de Yacila, extremo norte del Perú". Bulletin de l'Institut Français d'Etudes Andines, 24 (2), p. 213-243.

Jennings, Justin y Willy Yépez

2009 "El período Intermedio Tardío en el Valle de Cotahuasi, Arequipa, Perú". Andes 7; p. 421-440.

Lavallée, Danielle

1967 T”ypes céramiques des Andes Centrales du Pérou (Période intermédiaire récente)". Journal de la Société des Américanistes, 56 (2), p. 411-448.

Lavallée, Danielle y Michèle Julien

1983 Asto: curacazgo prehispánico de los Andes Centrales. Lima: IEP.

Lumbreras, Luis

1974 Chankas y Pocras. En Las Fundaciones de Huamanga. Hacia una Prehistoria de Ayacucho. Lima: Club de Huamanga. 
Meyers, Albert

1975 "Algunos problemas en la clasificación del estilo incaico". Pumapunku 8; p. 7-25.

Schreiber, Katharina

1982 Exploración Arqueológica del Valle Carahuarazo, Lucanas, Ayacucho, Perú. Informe final presentado al Centro de Investigación y Restauración de Bienes Monumentales. Instituto $\mathrm{Na}$ cional de Cultura. Lima.

1987 “Conquista y consolidación: Una comparación entre las ocupaciones de los imperios Wari e Inka en un valle peruano de la Sierra”. Histórica. 9 (1), p. 55-85.

1992 "Wari imperialism in Middle Horizon Peru". Anthropological Papers 87. Michigan: University of Michigan.

1993 "The Inca occupation of the province of Andamarca Lucanas, Perú”. En Provincial Inca: Archaeological and Ethnohistorical Assessment of impact of the Inca State, M. Malpass (Ed.), p. 77-116. University of Iowa Press, Iowa City.
Valdez, Lidio

2002 "Y la tradición continua: la alfarería de la época Inka en el valle de Ayacucho, Perú". Boletín de Arqueología PUCP 6:395-410.

Valdez, Lidio y Ernesto Valdez

2002 "El valle de Ayacucho y el Tawantinsuyo". Arqueología y Sociedad 14, p. 77-98.

Wernke, Steve

2003 An Archeo-History of Andean Community and landscape: The Late Prehispanic and Early Colonial Colca Valley, Peru. Ph. D. Dissertation, Department of Anthropology, University of Wisconsin-Madison. 